\title{
The Inflammatory Process in Response to Nanoparticles
}

\author{
David M. Goncalves, Rafael de Liz, and Denis Girard \\ Laboratoire de Recherche en Inflammation et Physiologie des Granulocytes, \\ Université du Québec, INRS-Institut Armand-Frappier, 531 boulevard des Prairies, \\ Laval, QC, Canada H7V $1 B 7$
}

Received 16 November 2011; Accepted 16 November 2011

Today, numerous nanotechnology-derived applications are commercially available. More than 1000 products are already available on the market $[1,2]$. The use of nanoparticles (NPs) has increased in the past few years in various fields including defence, aerospace, electronics, biology, and medicine. Therefore as human exposure to NPs increases, so do investigations on their toxicity. In one hand, nanotoxicology can be seen as an important subdiscipline of toxicology, and, on the other hand, it also represents a subdiscipline of nanotechnology [3]. Studies show that many parameters such as the diameter, surface area, surface composition, and solubility, to name a few, can all have an effect on cell responses, cellular interactions, and reactive oxygen species (ROS) production. They can also have an effect on NP capacity to bind to certain proteins or receptors. More importantly these parameters and others have also the potential to influence an inflammatory response following NP exposure as it has been shown in many in vitro and in vivo studies [4-7]. It has often been demonstrated that smaller particles tend to induce greater inflammatory responses than their bigger counterparts of same chemical composition [5]. Although some NPs may possess proinflammatory activities, the use of others and NP techniques can be very useful in medicine; for example, they can be used for drug-delivery therapies and may also represent excellent biomarkers for the diagnosis of diverse diseases, including inflammatory diseases.

In an effort to increase our general knowledge regarding the inflammatory properties of NPs, this special issue of TheScientificWorldJOURNAL was planned in order to generate an important bibliographic tool in this emerging area of research.

As the main organ in which the effect of NPs has been (and is still) addressed in the literature is the lung, the first paper from K.-I. Inoue and H. Takano provides insights into the immunotoxicity of airborne and engineered NPs. It deals with the fact that such NPs act as an exacerbating factor on hyper susceptible subjects with immune-mediated pulmonary inflammation. Interestingly, this review put the emphasis on the fact that impairment of both innate and adaptive immunity following NP exposure may synergistically facilitate pathological pulmonary inflammation.

The second article is a contribution from M. Roursgaard and collaborators that also focuses on pulmonary inflammation, but by specifically investigating acute and subchronic airway inflammation of quartz and Titanium dioxide $\left(\mathrm{TiO}_{2}\right)$ agglomerates administered by intratracheal instillation in mice. Inflammation was evaluated from the bronchoalveolar lavage fluids content of inflammatory cells, the cytokines TNF- $\alpha$, and IL-6 as well as from lung histology. Using this approach, the inflammatory effects

Correspondence should be addressed to Denis Girard, denis.girard@iaf.inrs.ca

Copyright (C) 2011 David M. Goncalves et al. This is an open access article distributed under the Creative Commons Attribution License, which permits unrestricted use, distribution, and reproduction in any medium, provided the original work is properly cited.

Published by TheScientificWorldJOURNAL; http://www.tswj.com/ 
of two types of quartz (SRM1878a and DQ12) and the effects of different particle sizes and polymorphs of $\mathrm{TiO}_{2}$ NPs were compared in this study.

The third paper from Stevenson and colleagues is a review that covers the usefulness of NPs in medicine. They highlight the importance of using nanoparticle techniques in order to provide excellent biomarkers for either the diagnosis of inflammatory diseases or their progression. They discuss the merit of diverse approaches related to their possible application in inflammatory diseases.

The next paper conducted by M. Hayder and collaborators deals with the anti-inflammatory properties of dendrimers. They discuss how these NPs are attractive nanotools for applications, especially in biology and medicine. Interestingly, this review is based on the five main scientific articles dealing on the anti-inflammatory properties displayed by dendrimers.

The fifth article focuses on cumulative evidences observed by Y. Song and S. Tang in some patients exposed to NPs who present an unusual inflammatory pulmonary disease based on several distinct parameters. This paper confirms the importance of doing further research and collaborative efforts on nanosafety to prevent or, at least, minimize potential hazardous effects of NPs and nanomaterials to humans and environment.

Positioning the importance of neutrophils in inflammation, the last review from D. M. Gonçalves et al. summarizes the current literature regarding the activation of these cells by NPs. It represents certainly an important bibliographic tool for researchers interested in nanotoxiclogy or related fields, as well as in inflammation and in general neutrophil cell biology.

In summary, this special issue of TheScientificWorldJOURNAL deals with two aspects on NPs and inflammation that are not mutually exclusive: (1) the usefulness of NPs in general biology and medicine and (2) the evaluation of safety for using NPs. Studying the effects of NPs on the inflammation process is certainly a great step towards improving global knowledge about NPs in biology. Important discoveries will certainly emerge in the becoming years in this area of research.

\section{REFERENCES}

[1] A. D. Maynard, D. B. Warheit, and M. A. Philbert, "The new toxicology of sophisticated materials: nanotoxicology and beyond," Toxicological Sciences, vol. 120, pp. 109-129, 2011.

[2] A. D. Maynard, "Nanotechnology: the next big thing, or much ado about nothing?" Annals of Occupational Hygiene, vol. 51, no. 1, pp. 1-12, 2007.

[3] H. C. Fischer and W. C. Chan, "Nanotoxicity: the growing need for in vivo study," Current Opinion in Biotechnology, vol. 18, no. 6, pp. 565-571, 2007.

[4] A. Nel, T. Xia, L. Madler, and N. Li, "Toxic potential of materials at the nanolevel," Science, vol. 311, no. 5761, pp. 622-627, 2006.

[5] G. Oberdorster, E. Oberdorster, and J. Oberdorster, "Nanotoxicology: an emerging discipline evolving from studies of ultrafine particles," Environmental Health Perspectives, vol. 113, no. 7, pp. 823-839, 2005.

[6] K. Peters, R. E. Unger, C. J. Kirkpatrick, A. M. Gatti, and E. Monari, "Effects of nano-scaled particles on endothelial cell function in vitro: Studies on viability, proliferation and inflammation," Journal of Materials Science, vol. 15, no. 4, pp. 321-325, 2004.

[7] J. A. Shatkin, L. C. Abbott, A. E. Bradley et al., "Nano risk analysis: advancing the science for nanomaterials risk management," Risk Analysis, vol. 30, no. 11, pp. 1680-1687, 2010.

\section{This article should be cited as follows:}

David M. Goncalves, Rafael de Liz, and Denis Girard, "The Inflammatory Process in Response to Nanoparticles," TheScientificWorldJOURNAL, vol. 11, pp. 2441-2442, 2011. 

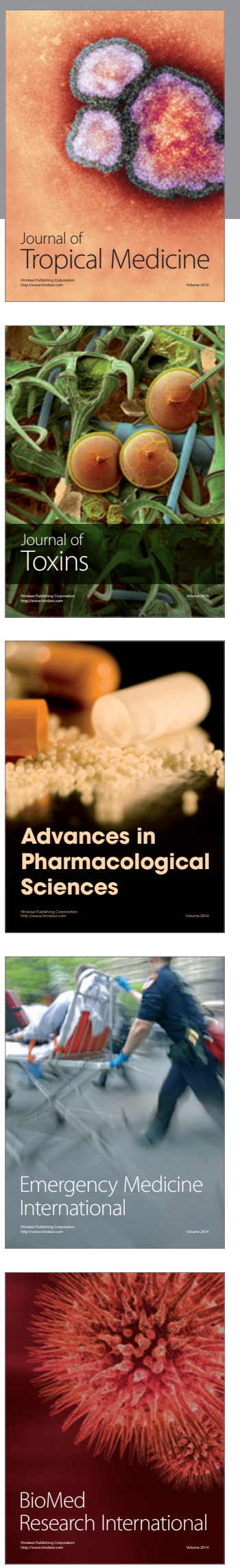
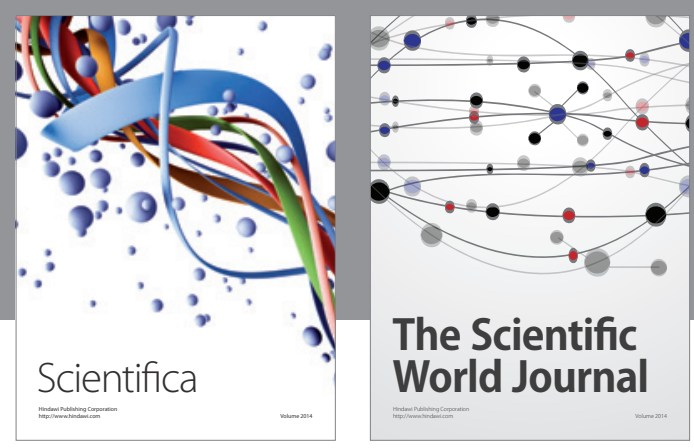

The Scientific World Journal
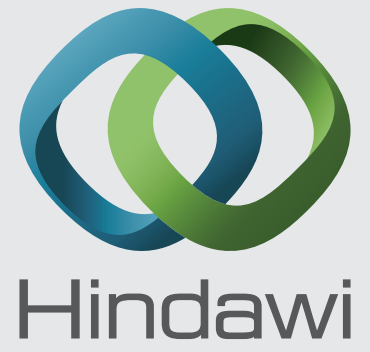

Submit your manuscripts at

http://www.hindawi.com
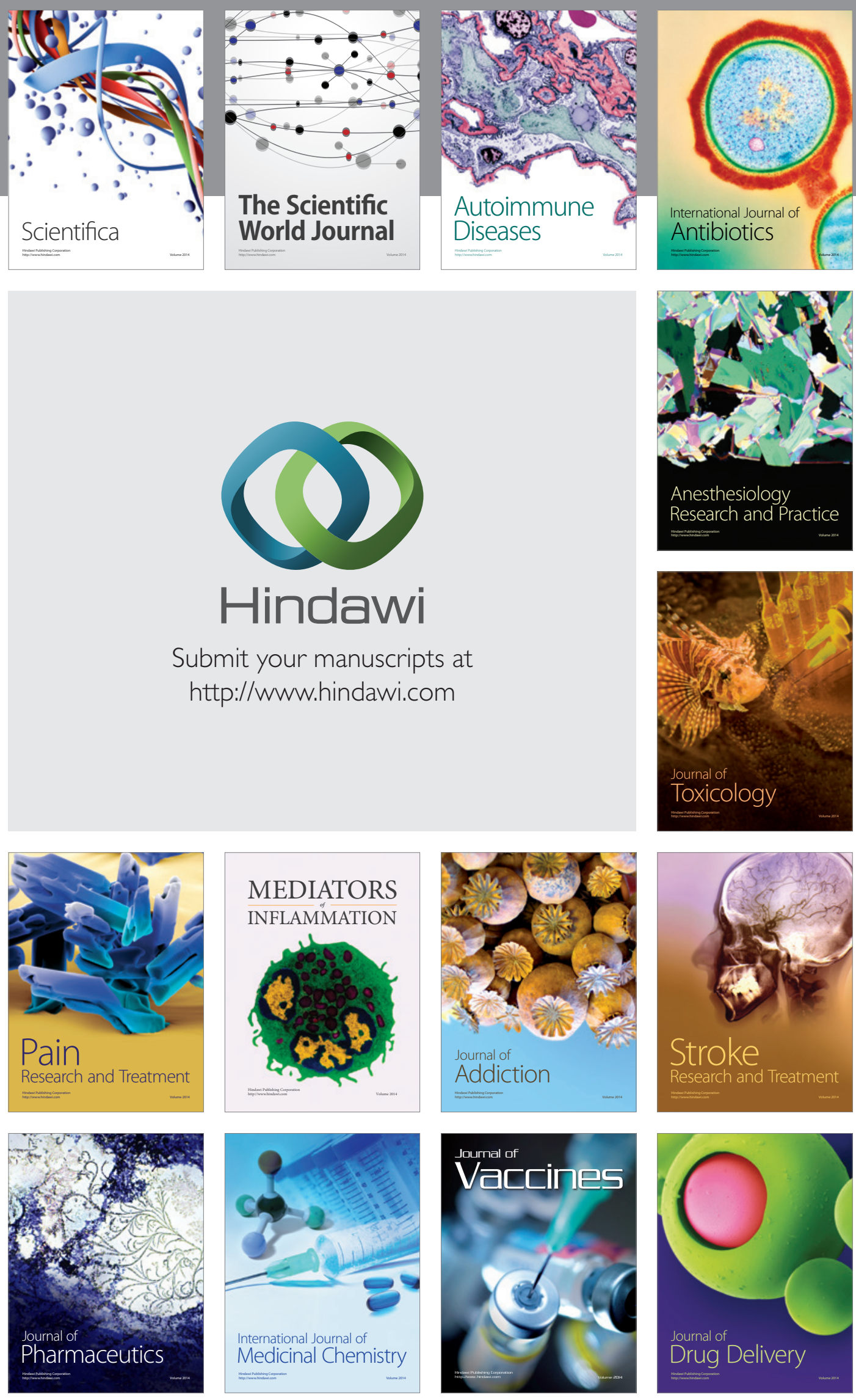